\title{
Crohn's disease and the Melkersson-Rosenthal syndrome
}

Alexandra Ilnyckyj MD, Thomas AM Aldor MB BS, Richard Warrington MD, Charles N Bernstein MD

A Ilnyckyj, TAM Aldor, R Warrington, CN Bernstein. Crohn's disease and the Melkersson-Rosenthal syndrome. Can J Gastroenterol 1999;13(2):152-154. A 30-year-old woman with a 10-year history of recurrent bloody diarrhea and documented colitis of the descending colon, consistent with Crohn's disease, presented with an exacerbation of her gastrointestinal disease and an 18-month history of recurrent facial and genital swelling. Her course evolved to include severe ear pain, dysphagia and colonic dysmotility. She was diagnosed with Melkersson-Rosenthal syndrome and treated with multiple agents. The neurological aspects of her presentation are highlighted, and the Melkersson-Rosenthal syndrome is reviewed.

Key Words: Crohn's disease, Granulomatous diseases, Melkersson-Rosenthal syndrome

\author{
Maladie de Crohn et syndrome de \\ Melkersson-Rosenthal
}

RÉSUMÉ : Une femme de 30 ans, présentant des antécédents de diarrhées sanguinolentes récurrentes depuis 10 ans et une colite documentée au côlon descendant concordant avec le diagnostic de maladie de Crohn s'est présentée avec une exacerbation de sa maladie gastro-intestinale et après avoir présenté pendant 18 mois un œè̀me récurrent au visage et aux organes génitaux. Son état a évolué et la patiente souffrait d'une douleur intense à l'oreille, de dysphagie et de dysmotilité colonique. Elle a reçu un diagnostic de syndrome de Melkersson-Rosenthal et a été traitée au moyen de multiples agents. Les aspects neurologiques de ce tableau clinique sont soulignés ici et on passe en revue le syndrome de Melkersson-Rosenthal.
$T^{2}$ he Melkersson-Rosenthal syndrome is a rare entity (1) of facial and genital swelling, facial nerve palsy and tongue changes. Noncaseating granulomas are seen on histology. Clinical and histological similarities between Crohn's disease and the Melkersson-Rosenthal syndrome raise the issue as to whether Melkersson-Rosenthal is a form fruste of Crohn's disease. A woman who was initially diagnosed with Crohn's disease but whose clinical features evolved into Melkersson-Rosenthal syndrome is reported. We suggest that the features of her case are sufficiently distinct from those of Crohn's disease that Melkersson-Rosenthal syndrome and Crohn's disease should be viewed as distinct entities.

\section{CASE PRESENTATION}

A 30-year-old woman with a previous diagnosis of Crohn's colitis was evaluated in light of symptom recur- rence with new clinical features. She had been diagnosed with Crohn's disease on the basis of recurrent bloody diarrhea, requiring hospitalization on two occasions. Seven years earlier, colonoscopy demonstrated multiple aphthous ulcerations to $50 \mathrm{~cm}$ with a stricture at $48 \mathrm{~cm}$. The rectum was spared, and there was normal mucosa beyond the descending colon to the cecum. Biopsies revealed markedly increased mixed inflammatory infiltrate in the lamina propria consisting of plasma cells, eosinophils and neutrophils. Crypt abscesses and cryptitis were identified, and there was extensive superficial ulceration. The inflammatory process was focal, with adjacent areas completely spared of the acute inflammatory process. There was no crypt architecture distortion, and no granulomas were seen.

At assessment, the patient reported a six-month history of worsening bloody diarrhea associated with a $22.7 \mathrm{~kg}$

Department of Internal Medicine, University of Manitoba, Winnipeg, Manitoba

Correspondence: Dr Charles N Bernstein, Section of Gastroenterology, University of Manitoba, GB445 Health Sciences Centre, 820 Sherbrook Street, Winnipeg, Manitoba R3A 1R9. Telephone 204-787-1434, fax 204-787-4826, e-mail

cbernst@cc.umanitoba.ca 


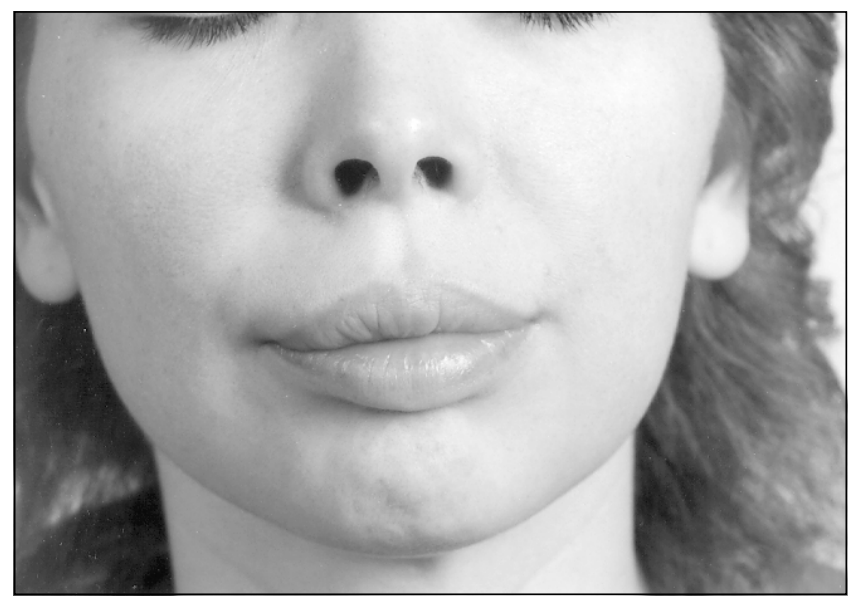

Figure 1) Swelling of the upper and lower lips is evident, with greater prominence on the right

weight loss and dyspareunia. She also reported 18 months of intermittent genital and lip swelling. A gynecologist documented vulvar and labial swelling with superficial ulceration and tender inguinal lymphadenopathy. There was no evidence of sexually transmitted disease, and the results of a pelvic ultrasound were normal. Her lip swelling had been assessed by a dentist and an otolaryngologist, but no cause was established. A lip biopsy demonstrated noncaseating granulomas. The results of serology for Toxoplasma species, Brucella species, Francisella tularensis, Yersinia species, Borrelia burgdorferi, Epstein-Barr virus and non-lymphogranuloma venereum chlamydia were negative. The results of Mantoux skin testing were negative, with a concurrent positive anergy screen.

The results of immunoelectrophoresis, and antinuclear antibody, C4, immunoglobulin (Ig) G, IgA, IgM, IgE and $\mathrm{C} 1$ esterase inhibitor levels were all normal. C3 levels were mildly depressed at $0.85 \mathrm{~g} / \mathrm{L}$ (normal range 0.88 to $2.07 \mathrm{~g} / \mathrm{L}$ ). She had no fever, rashes, or musculoskeletal or respiratory complaints, and displayed no symptoms suggestive of perianal fistulas or abscesses.

Physical examination revealed a thin woman in no distress. Examination of the head and neck demonstrated a swollen upper lip bilaterally and a swollen right lower lip (Figures 1,2). Oral mucosa was normal. There was no lymphadenopathy, or evidence of cranial nerve palsies or other neuropathy. Results of cardiorespiratory and abdominal examinations were normal. Perineum was normal, and no inguinal nodes were noted. The skin and joints were also normal.

Ileocolonoscopy revealed edematous mucosa in the descending colon only, with slight narrowing at $45 \mathrm{~cm}$. There were three aphthous ulcers. The rest of the mucosa was normal. Results of multiple biopsies of the descending colon demonstrated mild reactive glandular changes, mild cryptitis and crypt abscesses, with chronic inflammation extending into the submucosa. No granulomas were seen. Results of biopsies from the ileum and remaining colon, and of barium studies of the esophagus, stomach and small

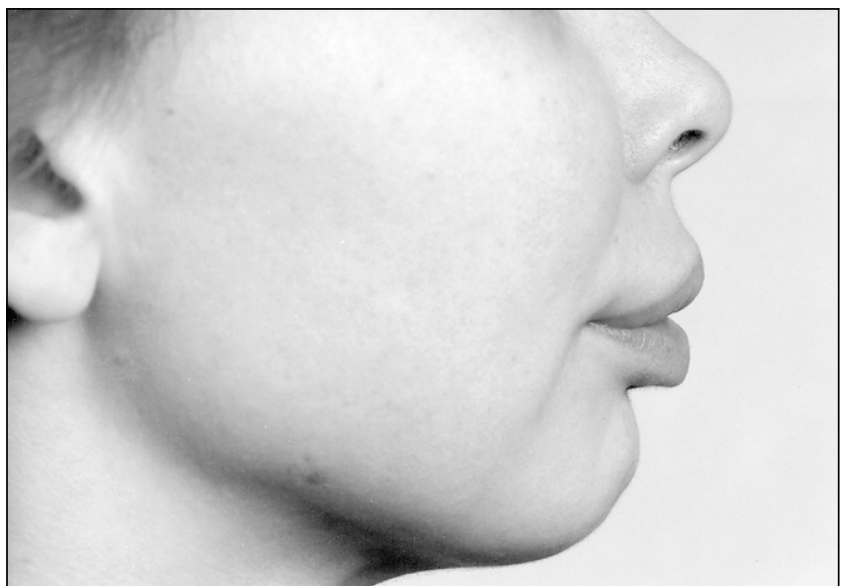

Figure 2) Right lateral view showing protuberance of the lips from swelling

intestine were all normal. Chest $\mathrm{x}$-ray results, complete blood cell count, blood chemistry panel and erythrocyte sedimentation rate were normal. The patient was diagnosed with Melkersson-Rosenthal syndrome. A course of prednisone and 5-acetylsalicylic acid (5-ASA) was initiated.

The patient's gastrointestinal complaints improved after a two-month treatment period; however, she could not be tapered from the prednisone. Her genital and facial swelling did not respond to corticosteroid treatment. 6Mercaptopurine $50 \mathrm{mg} / \mathrm{day}$ was added to her therapy. Five months after the initial consultation, the patient returned to her physician, complaining of severe right ear pain associated with subjective hearing loss requiring narcotics. $\mathrm{Re}$ sults of the regional examination were normal. She was assessed by an oral surgeon and an otolaryngologist; no diagnosis was established. Results of the audiometric evaluation and computed tomography scans were normal. The patient's abdominal pain and diarrhea improved with the institution of morphine sulphate for her ear pain. Her facial and genital swelling coupled with ear pain dominated her clinical presentation; these symptoms persisted and were her primary complaints at all further clinic visits. Her prednisone therapy was reduced. She again developed painful inguinal lymphadenopathy, and the results of lymph node biopsies revealed noncaseating granulomas. Nodal tissue was examined extensively for Mycobacteria species and fungi; the results were negative.

The patient was treated with hydroxychloroquine 400 mg twice daily in addition to her 6-mercaptopurine and 5 ASA. There was no change in her status after a threemonth trial, and the hydroxychloroquine was discontinued. She was subsequently treated with a three-month trial of clofazimine $200 \mathrm{mg}$ weekly, with no initial improvement. However, she was successfully tapered from her prednisone over the next three months, with no complaints of diarrhea or abdominal pain, and she has remained on clofazimine for two years. She developed dysphagia for solids and severe constipation requiring 
multiple laxatives including electrolytes/polyethylene glycol (GoLytely, Baxter Corporation) and oral sodium phosphate (Fleet Phospho-Soda, Johnson \& Johnson) six months into her therapy with clofazimine. These symptoms worsened despite that her chronic morphine use did not increase. She had no signs of autonomic instability. Results of investigations including esophagogastroduodenoscopy, esophageal motility and flexible sigmoidoscopy were normal. The results of a radio-opaque Sitzmark study were abnormal, demonstrating colonic inertia. Twentyone of 24 markers were evenly distributed throughout the colon at day 10 after consumption of the Sitzmark capsule.

The patient's facial and genital swelling persist, and she remains dependant on narcotics due to ear pain. She continues to suffer from dysphagia and severe constipation. Her abdominal pain and bloody diarrhea remain in remission. At present, her medications include 6-mercaptopurine $50 \mathrm{mg}$ daily, clofazimine $200 \mathrm{mg}$ daily, 5-ASA $4.0 \mathrm{~g}$ daily and morphine. She is receiving acupuncture therapy in an attempt to relieve her swelling and pain.

\section{DISCUSSION}

Melkersson-Rosenthal syndrome is a rare condition characterized by a triad of recurrent oral-facial swelling, commonly affecting the lips, intermittent facial nerve palsy and tongue changes of lingua plicata. More commonly, only lip swelling is observed and has been termed Miescher's cheilitis granulomatosa (2). Vulvar swelling has also been described (3). Many neurological manifestations have been reported, including hyperacusia, acroparesthesia and blepharospasm (2). Autonomic neuropathy of the colon has also been described in children with the syndrome (personal communication). Histologically, the defining feature is the presence of noncaseating epitheliod granulomas (3).

The underlying etiology and pathogenesis of Melkersson-Rosethal are unknown, but theories include an allergic reaction, an infective process and a vasomotor disorder of the vasa vasorum (2). Therapeutic strategies include anti-inflammatory drugs such as intralesional or systemic corticosteroids, clofazimine or hydroxychloroquine, and antibiotics such as minocycline or metronidazole. Surgical reduction is occasionally practised with reports of exaggerated recurrence (personal communication). Intermittent electroacupuncture to affected mucocutaneous areas has been found to be beneficial in 20 of 22 patients in an unpublished case series (personal communication). The natural history is unknown.

The overlap in histology between MelkerssonRosenthal syndrome and Crohn's disease has raised the question as to whether Melkersson-Rosenthal is a form fruste of Crohn's disease (4). Although the German language literature discusses this relationship, there is only one case report in the English language literature of a patient manifesting features of Melkersson-Rosenthal syn- drome and possible Crohn's disease (4). Other granulomatous diseases, including Behçet's syndrome, Wegener's granulomatosis and sarcoidosis are also differential diagnoses; however, our patient did not have clinical features indicative of these entities. Oral lesions may be seen in Crohn's disease, including aphthous ulcers, cheilitis, fissures and deep ulcers, none of which our patient had $(5,6)$. Asymmetric lip swelling associated with granulomatous histological changes is a very unusual manifestation of Crohn's disease. Vaginal Crohn's disease is typically reported as ulceration $(7,8)$, associated with fistulas or an extension from other disfiguring perianal lesions $(9,10)$. Our patient had superficial ulceration of her labia, but her predominant vaginal lesion was painful swelling. Concurrent oral labial and vaginal swelling is highly unusual for Crohn's disease.

Our patient's genital and lip swelling, coupled with a lip biopsy demonstrating granulomas, indicate MelkerssonRosenthal syndrome. Her ear pain associated with subjective hearing loss, as well as her colonic inertia and dysphagia, are the more rarely described neurological features of this syndrome. Although she was on a dose of morphine sulphate when her colonic inertia developed, it was a stable dose, and her bowel movements were regular for several months while on the morphine sulphate before the occurrence of her constipation. Furthermore, her constipation did not improve when her morphine doses were lowered. Our view is that her segmental colitis represents an aspect of Melkersson-Rosenthal syndrome. The predominance of clinical features suggestive of neurological abnormalities and the rarity of granulomatous inguinal adenopathy in Crohn's disease lead us to speculate that this patient has a single diagnosis of Melkersson-Rosenthal syndrome. Furthermore, we suggest that Crohn's disease and Melkersson-Rosenthal syndrome are two distinct entities.

ACKNOWLEDGEMENTS: The authors thank Dr OP Hornstein and Dr G Schuler of Erlangen, Germany for their thoughful advice regarding this patient.

\section{REFERENCES}

1. Daoud MS, Rogers RS. Melkersson-Rosenthal syndrome. Semin Dermatol 1995;14:135-9.

2. Wadlington WB, Riley HD, Lowbeer L. The Melkersson-Rosenthal syndrome. Pediatrics 1984;74:502-6.

3. Sussman GL, Yang WH, Steingerg S. Melkersson-Rosenthal syndrome: clinical, pathologic, and therapeutic considerations. Ann Allergy 1992;69:187-94.

4. Lloyd DA, Payton KB, Geunther L, Frydman W. MelkerssonRosenthal syndrome and Crohn's disease: one disease or two? J Clin Gastroenterol 1994;18:213 -7.

5. Basu MK, Asquith P. Oral manifestations of inflammatory bowel disease. Clin Gastroenterol 1980;9:307-21.

6. Talbot T, Jewell L, Schloss E, Yakimets W, Thomson ABR. Cheilitis antedating Crohn's disease: Case report and literature update of oral lesions. J Clin Gastroenterol 1984;6:349-54.

7. Kremer M, Nussenson E, Steinfeld M, Zuckerman P. Crohn's disease of the vulva. Am J Gastroenterol 1984;79:376-8.

8. Freeman HJ, Kwong R, Sacks SL. Granulomatous vaginal 
ulceration due to metastatic cutaneous Crohn's disease. Can J Gastroenterol 1995;9:183-6.

9. Hughes LE, Taylor BA. Perianal lesions in Crohn's disease. In: Allan RN, Keighley MRB, Alexander-Williams J, Hawkins CF, eds. Inflammatory Bowel Diseases. Edinburgh: Churchill-Livingstone, 1990:351-61.

10. Heyen F, Winslet MC, Andrews H, Alexander-Williams J, Keighley MRB. Vaginal fistulas in Crohn's disease. Dis Colon Rectum 1989;32:379-83. 


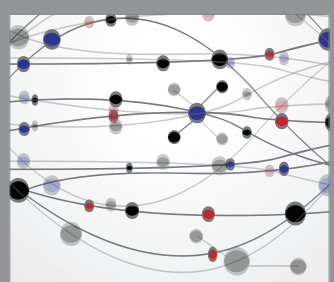

The Scientific World Journal
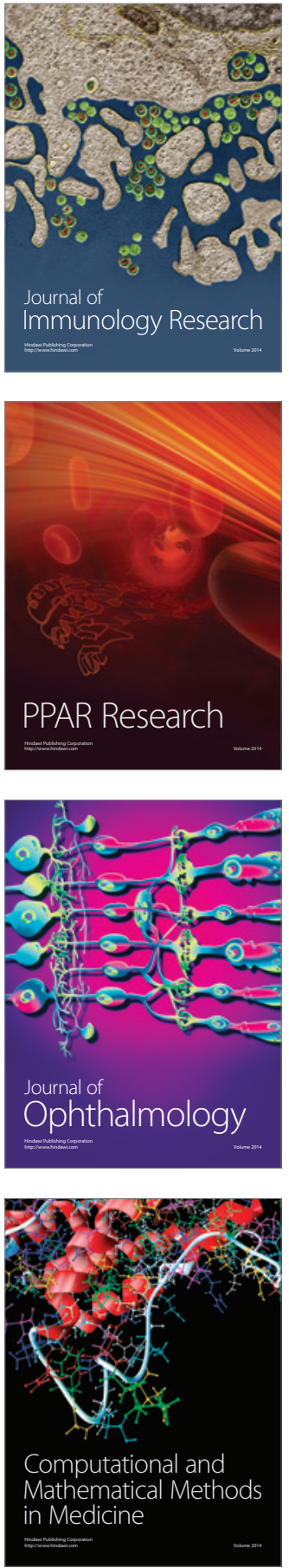

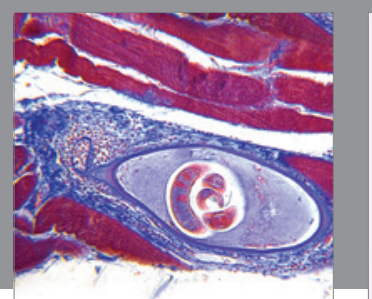

Gastroenterology Research and Practice

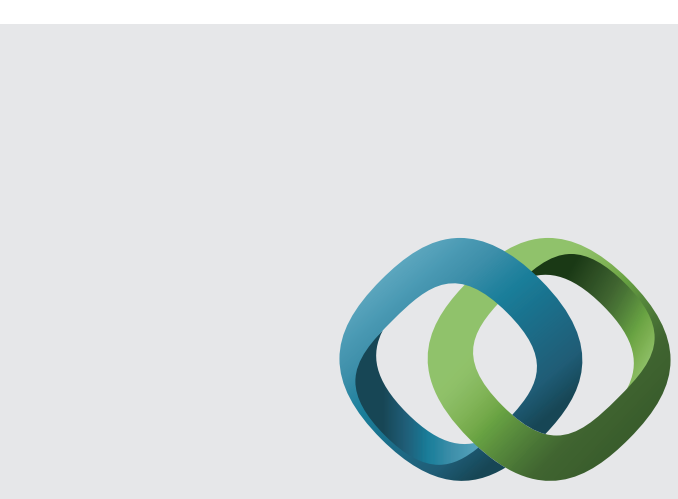

\section{Hindawi}

Submit your manuscripts at

http://www.hindawi.com
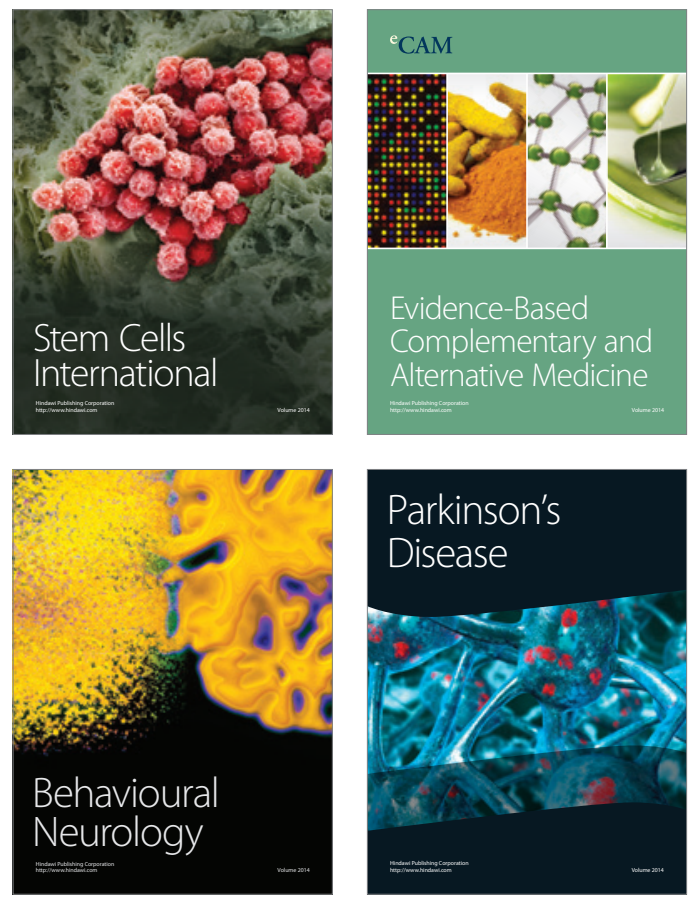
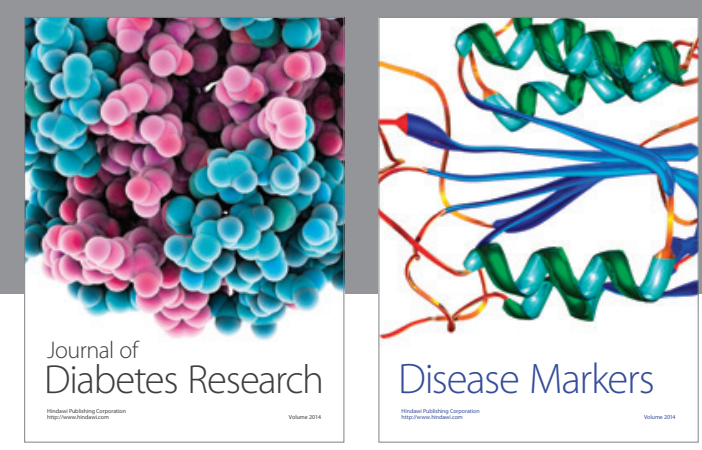

Disease Markers
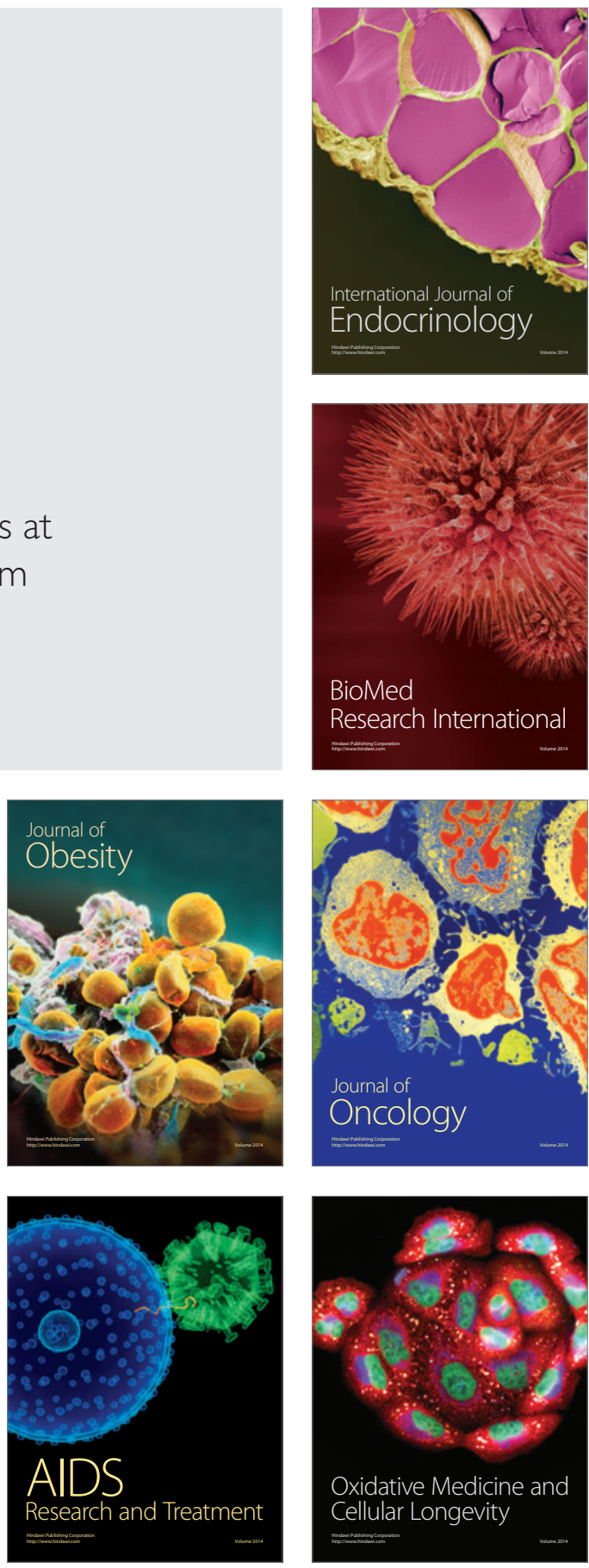